\title{
Can Warm, Humidified High-Flow Filtered Air Therapy Be Protective Against Severe Infection from Sars-Cov-2 and Other Respiratory Pathogens?
}

\author{
Shaili Amatya ${ }^{1 *}$, Jennifer Erkinger ${ }^{2}$, Roopa Siddaiah ${ }^{3}$ and Joanna Floros ${ }^{1,4}$ \\ ${ }^{1}$ Division of Neonatal-Perinatal Medicine, Center for Host Defense, Inflammation and Lung Disease (CHILD) Research, Department of Pediatrics, \\ Pennsylvania State University College of Medicine, USA \\ ${ }^{2}$ Department of Respiratory Care, Penn State Hershey Medical Center/Penn State Hershey Children's Hospital, USA \\ ${ }^{3}$ Division of Pediatric Pulmonology, Cystic Fibrosis and Sleep Medicine, Department of Pediatrics, Pennsylvania State University College of Medicine, USA \\ ${ }^{4}$ Obstetrics \& Gynecology, Pennsylvania State University College of Medicine, USA \\ *Corresponding author: Shaili Amatya, Assistant Professor, Division of Neonatal-Perinatal Medicine, Center for Host Defense, \\ Inflammation and Lung Disease (CHILD) Research, Department of Pediatrics, Pennsylvania State University College of Medicine, \\ 500 University Drive, P.O. Box 850, Hershey, PA 17033-0850, USA.
}

To Cite This Article: Shaili Amatya, Jennifer Erkinger, Roopa Siddaiah, Joanna Floros. Can Warm, Humidified High-Flow Filtered Air Therapy Be Protective Against Severe Infection from Sars-Cov-2 and Other Respiratory Pathogens?. Am J Biomed Sci \& Res. 2021 - 13(6). AJBSR.MS.ID.001937. DOI: 10.34297/AJBSR.2021.13.001937.

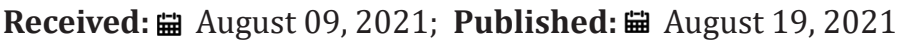

Keywords: Respiratory, Infection, Humidification, High Flow Therapy

\section{Minireview}

The scientific article "Impact of surfactant protein-A variants on survival in aged mice in response to Klebsiella pneumoniae infection and ozone: serendipity in action" [1] investigated the effect of infection and oxidative stress, along with the impact of surfactant protein A (SP-A) genetic variants on the survival of aged mice. This study, along with a prior study [2] investigating survival after infection in young mice, compared survival among humanized transgenic expressing each a different human SP-A variant $\left(6 \mathrm{~A}^{2}\right.$, $\left.6 A^{4}, 1 A^{0}, 1 A^{3}, K O\right)$. The aged mice were first exposed to either ozone (a surrogate for pollution-induced lung injury) delivered via a high flow of warmed humidified filtered air (FA) or high flow of warmed humidified FA or room air, with the latter two serving as controls for ozone exposure. The young mice were exposed to high flow of warmed humidified FA or room air. Next, all the mice were exposed to oropharyngeal Klebsiella pneumoniae. As expected, the mice exposed to ozone and infection had lower survival compared to the two controls.
However, this study [1] had an interesting secondary result. The mice exposed to FA (that provided warmed at $37^{\circ} \mathrm{C}$, humidified, high flow air at 15 liters per minute (LPM) with $\sim 1.5 \mathrm{~cm}$ of $\mathrm{H}_{2} 0$ positive pressure in the experiment chamber) had better survival compared to mice that were on room air before infection. The improved survival was true for both young and aged mice, albeit the magnitude of improvement was more prominent in the aged mice. This finding has posed a curious clinical question of whether the use of warmed, humidified, high flow nasal therapy (HFNT) lessens the risk of severe infection resulting in high morbidity and mortality in the at-risk older population from COVID-19 and other respiratory pathogens. Studies have shown the clinical utility of HFNT in patients with acute respiratory distress syndrome (ARDS) secondary to COVID-19 infection who have not tolerated continuous positive airway pressure (CPAP) or noninvasive ventilation (NIV) $[3,4]$. However, empiric use of HFNC in a high-risk population with a history of exposure to infection or the early stages of infection, to 
prevent worsening clinical sequelae has not yet been explored. This editorial discusses possible mechanisms of the warmed, humidified, high flow air therapy affecting lung infection susceptibility.

High flow nasal cannula (HFNC) delivers warmed, humidified air at up to 60 LPM $[5,6]$. HFNC improves pulmonary function by providing positive distending pressure [7] to increase functional residual capacity and improve alveolar recruitment [8]. It also provides nasopharyngeal dead space washout, nasopharynx distension [8,9], decreased work of breathing [10], and improves gas exchange. In addition, the warmed, humidified air to the conducting airways improves pulmonary compliance and conductance [5,8]. In the clinical setting, HFNC is used for multiple indications, such as post-extubation therapy [11] and to reduce intubation $[12,13]$ in patients with respiratory failure [14].

In the current article [1], the authors postulated that the filtered air induced positive distending pressure that improved lung reserve, alveolar recruitment, and reduced ventilation-perfusion (VQ) mismatch. It was also noted that the greater alveolar recruitment prior to the introduction of the infection provides a larger lung surface area for the spread of the pathogen. In addition, the relative decrease in bacterial density allows the lung host defense system to be more efficient. However, the high FA flow exposure was not directed nasally on these mice, as it would be in a clinical setting. Therefore, it is challenging to determine the actual distending pressure generated in the lower airways when mice are exposed to the high FA flow chamber. Nevertheless, it would be substantially different from the mice exposed to room air, given that the high FA flow is administered in a confined chamber. Although there is no direct evidence that HFNC prevents infection or attenuates disease severity, a few studies have demonstrated that HFNC leads to a decreased risk of ventilator-associated pneumonia and nosocomial pneumonia than invasive ventilation [12]. However, this may be true for other forms of non-invasive ventilation and not just for HFNC.

To better understand how high FA flow may affect pathogen delivery or entry to the lung, reviewing HFNC with aerosol medication delivery may provide answers. During the aerosol delivery via HFNC, the delivery dose is inversely proportional to the gas flow [15]. This relation of delivery dose and gas flow is explained as the high-gas-flow generating turbulence leads to aerosol particle loss during the upper airway passage and decreases the dose of the particles reaching the lower airway [16]. However, this phenomenon also does not explain the improved survival in mice exposed to FA as the pathogen was introduced after the high flow exposure.

Humidified high airflow as done by HFNC has been shown to have a decreased trans-nasal aerosol medication delivery compared to dry air $[16,17]$. In addition, the aerosol delivery via
HFNC may depend on the ratio of high airflow to patient inspiratory airflow than high airflow by itself, so the aerosol deposition is higher in distressed breathing than quiet breathing [18]. The ozone exposed mice may have respiratory distress, making them prone to increased pathogen deposition than controls. However, all the mice were anesthetized before the pathogen exposure and had similar inspiratory airflow; therefore, the distressed/quiet breathing speculation does not explain the different outcomes in the FA mice. The humidified air protects the airway mucosa $[9,19]$ via mucociliary clearance [20]. This phenomenon was also shown by Hasani et al., as warmed humidified high airflow was given to bronchiectasis patients for 3 hours per day and subsequently improved the measured tracheobronchial mucociliary clearance [21]. Therefore, it is plausible that the mice exposed to FA had improved survival after exposure to pathogen due to improved mucociliary clearance of the lower airways compared to room air control mice. Although ozone was delivered via a high warmed humidified FA flow, the ozone-exposed mice would continue to show poor outcomes due to the oxidative stress injury. Interestingly, there has been literature regarding the use of prone position to increase oxygenation and improve outcomes in COVID 19 patients [22]. However, upon further investigation, it was determined that all study mice were placed prone after the respiratory pathogen exposure, thus eliminating this factor as a possibility of a favorable outcome in one group versus the other.

\section{Conclusion}

In conclusion, this original research paper [1] shows an exciting finding via serendipity and has put forth a fascinating idea with potential clinical benefits that has also been discussed by Abbasi et al. [23]. The use of warmed air humidification may be a simple yet effective therapy to prevent or reduce morbidity and mortality due to SARS-CoV2 or other pathogens in the at-risk older population. Although a Cochrane review [24] in 2017 stated that there was no benefit or harm from the use of warmed, humidified air to treat the common cold, the authors did acknowledge the quality of evidence was low. Nevertheless, given the physiological basis of warmed, humidified high airflow therapy on improved mucociliary clearance, positive airway pressure, and possible reduction of respiratory infection, this study does warrant further clinical and basic science research consideration. In addition, investigation of the effects of warmed humidified high airflow therapy on infection susceptibility in the current pandemic of COVID-19 and other pulmonary diseases due to viral or bacterial infections is warranted.

\section{References}

1. Thorenoor N, S Phelps D, Kala P, Ravi R, Floros Phelps A, et al. (2020) Impact of Surfactant Protein-A Variants on Survival in Aged Mice in Response to Klebsiella pneumoniae Infection and Ozone: Serendipity in Action. Microorganisms 8(9): 1276 
2. Thorenoor N, Umstead TM, Zhang X, Phelps DS, Floros J, et al. (2018) Survival of surfactant protein-A1 and SP-A2 transgenic mice after Klebsiella pneumoniae infection, exhibits sex-, gene-, and variant specific differences; treatment with surfactant protein improves survival. Front Immunol 9: 2404.

3. AG Kaya, M Öz, S Erol, F Çiftçi, A Çiledağ, et al. (2020) High flow nasal cannula in COVID-19: a literature review," Tuberk Toraks 68(2): 168174.

4. Procopio G, Cancelliere A, Trecarichi EM, Mazzitelli M, Arrighi E, et al (2020) Oxygen therapy via high flow nasal cannula in severe respiratory failure caused by Sars-Cov-2 infection: a real-life observational study. Ther Adv Respir Dis 14: 1753466620963016.

5. Gotera C, Lobato SD, Pint T, Winck JC (2013) Clinical evidence on high flow oxygen therapy and active humidification in adults. Rev Port Pneumol 19(5): 217-227.

6. Groves N and Tobin A (2007) High flow nasal oxygen generates positive airway pressure in adult volunteers. Aust Crit Care 20(4): 126-131.

7. Spence KL, Murphy D, Kilian C, Mc Gonigle R, Kilani A, et al. (2007) Highflow nasal cannula as a device to provide continuous positive airway pressure in infants. J Perinatol 27(12): 772-775.

8. Dysart K, Miller TL, Wolfson MR, Shaffer TH (2009) Research in high flow therapy: mechanisms of action. Respiratory medicine 103(10): 1400-1405.

9. Chao KY, Chen YL, Tsai LY, Chien YH, Mu SC, et al. (2017) The role of heated humidified high-flow nasal cannula as noninvasive respiratory support in neonates. Pediatr Neonatol 58(4): 295-302.

10. Saslow JG, Aghai ZH, Nakhla TA, Hart JJ, Lawrysh R, et al. (2006) Work of breathing using high-flow nasal cannula in preterm infants. J Perinatol 26(8): 476-480.

11. Holleman-Duray D, Kaupie D, Weiss MG (2007) Heated humidified high-flow nasal cannula: use and a neonatal early extubation protocol. J Perinatol 27(12): 776-781.

12. Sztrymf B, Messika J, Bertrand F, Hurel D, Leon R, et al. (2011) Beneficial effects of humidified high flow nasal oxygen in critical care patients: a prospective pilot study. Intensive care medicine 37(11): 1780-1786.
13. Ward JJ (2013) High-flow oxygen administration by nasal cannula for adult and perinatal patients. Respir Care 58(1): 98-122.

14. Spoletini G, Alotaibi M, Blasi F, Hill NS (2015) Heated humidified highflow nasal oxygen in adults. Chest 148(1): 253-261.

15. Madney YM, Fathy M, Elberry AA, Rabea H, Abdelrahim ME, et al. (2019) Aerosol delivery through an adult high-flow nasal cannula circuit using low-flow oxygen. Respir Care 64(4): 453-461.

16. Li J, Fink JB, Mac Loughlin R, Dhand R (2020) A narrative review on trans-nasal pulmonary aerosol delivery. Critical Care 24(1): 1-13.

17. Alcoforado L, Ari A, Barcelar JDM, Brandão SCS, Fink JB, et al. (2019) Impact of gas flow and humidity on trans-nasal aerosol deposition via nasal cannula in adults: a randomized cross-over study. Pharmaceutics 11(7): 320 .

18. Li J, Gong L, Fink JB (2019) The ratio of nasal cannula gas flow to patient inspiratory flow on trans-nasal pulmonary aerosol delivery for adults: an in vitro study. Pharmaceutics 11(5): 225.

19. Woodhead DD, Lambert DK, Clark JM, Christensen RD (2006) Comparing two methods of delivering high-flow gas therapy by nasal cannula following endotracheal extubation: a prospective, randomized, masked, crossover trial. J Perinatol 26(8): 481-485

20. Shelly M (2006) The humidification and filtration functions of the airways. Respir Care Clin N Am 12(2): 139-148.

21. Hasani A, Chapman TH, Mc Cool D, Smit RE, Dilworth JP, et al. (2008) Domiciliary humidification improves lung mucociliary clearance in patients with bronchiectasis. Chron Respir Dis 5(2): 81-86.

22. Mittermaier M, Pickerodt P, Kurth F, de Jarcy LB, Uhrig A, et al. (2020) Evaluation of PEEP and prone positioning in early COVID-19 ARDS. EClinical Medicine 28: 100579.

23. Abbasi A, Phelps DS, Ravi R, Floros J (2021) Can Prophylactic High Flow of Humidified and Warmed Filtered Air Improve Survival from Bacterial Pneumonia and SARS-CoV-2 in Elderly Individuals? The Role of Surfactant Protein A. Antioxidants(Basel) 10(5): 640.

24. M Singh, M Singh, N Jaiswal, A Chauhan (2017) Heated, humidified air for the common cold. Cochrane Database Syst Rev 8(8): CD001728. 